\title{
The absorption of oral morroniside in rats: In vivo, in situ and in vitro studies
}

\author{
SHAN XIONG $1,2,3 *$ \\ JINGLAI LI ${ }^{4}$ \\ YANLING $\mathrm{MU}^{1}$ \\ ZHENQING ZHANG \\ ${ }^{1}$ Institute of Materia Medica, Shandong \\ Academy of Medical Sciences, Jinan \\ China \\ ${ }^{2}$ Key Laboratory for Biotech-Drugs \\ Ministry of Health, Jinan, China \\ ${ }^{3}$ Key Laboratory for Rare and Uncommon \\ Diseases of Shandong Province, Jinan \\ China \\ ${ }^{4}$ Key Laboratory of Drug Metabolism \\ and Pharmacokinetics, Beijing Institute \\ of Pharmacology and Toxicology, Beijing \\ China
}

Accepted October 14, 2018

Published online November 9, 2018

\begin{abstract}
Morroniside is one of the most important iridoid glycosides from Cornus officinalis Sieb. et Zucc. In the present study, the pharmacokinetics and bioavailability studies of morroniside were conducted on Sprague-Dawley (SD) rats. A rat in situ intestinal perfusion model was used to characterize the absorption of morroniside. Caco-2 cells were used to examine the transport mechanisms of morroniside. The pharmacokinetic study of morroniside exhibited linear dose-proportional pharmacokinetic characteristics and low bioavailability (4.3\%) in SD rats. Its average $P_{\text {eff }}$ value for transport across the small intestinal segments changed from $(3.09 \pm 2.03) \times 10^{-6}$ to $(4.53 \pm 0.94) \times$ $10^{-6} \mathrm{~cm} \mathrm{~s}^{-1}$. In Caco-2 cells, the $P_{\text {app }}$ values ranged from $(1.61 \pm 0.53) \times 10^{-9}$ to $(1.19 \pm 0.22) \times 10^{-7} \mathrm{~cm} \mathrm{~s}^{-1}$ for the apical to basolateral side and the $P_{\text {ratio }}$ values at three concentrations were all lower than 1.2. Morroniside showed poor absorption and it might not be a specific substrate of P-glycoprotein (P-gp).
\end{abstract}

Keywords: morroniside, pharmacokinetics, absorption, rats, in situ single-pass intestinal perfusion, Caco-2 cell

Morroniside, one of the most important iridoid glycosides, is the main active ingredient of Cornus officinalis Sieb. et Zucc. It is a rich source of iridoid glycosides and has been used as a traditional Chinese medicinal herb for centuries (1). Various pharmacological studies have indicated that morroniside was effective in the treatment of Alzheimer's disease (2) for protecting nerves (3), preventing diabetic liver damage (4) and renal damage (5), having beneficial effects on lipid metabolism and inflammation $(6,7)$ and anti-anaphylactic activity (8). In recent studies, morroniside displayed protective actions against the cytotoxicity produced by exposure to $\mathrm{H}_{2} \mathrm{O}_{2}$ in human SH-SY5Y cells $(9,10)$. In addition, morroniside could protect ischemia/reperfusion-induced brain injury by decreasing caspase- 3 activity, reducing the infarction volume, minimizing oxidative stress, etc. (11). Several research papers have been published on the pharmacological activity of ingredients of traditional Chinese medicines but few discuss their pharmacokinetic profiles, which are

\footnotetext{
*Correspondence; e-mail: shanxiong83@sohu.com
} 
essential. Pharmacokinetic profiles help elaborate the relationship between the intensity and time course of pharmacological events, the in vivo toxicological effects of ingredients, and extend the scope of the use and acceptance of different species (12).

In our previous work, the analytical methods for determination of morroniside in rat plasma and beagle dog plasma using LC-MS/MS were reported (13, 14). In addition, the excretion profile of morroniside in rats was investigated by a validated LC-MS/MS method (15).

Thus far, no research was done on the absorption kinetics of morroniside. In the present study, the absorption of oral morroniside was systematically investigated, in vivo, in situ and in vitro. The key absorption issues mentioned are addressed in support of the development of morroniside as a candidate drug.

\section{EXPERIMENTAL}

\section{Chemicals}

Morroniside (purity $>98.5 \%$ ) was extracted and purified in the Department of Pharmacology, Xuanwu Hospital of Capital Medical University (China). Hyperoside (IS) was purchased from the National Institute for the Control of Pharmaceutical and Biological Products (China). LC-MS grade methanol and acetonitrile were obtained from Thermo Fisher Scientific (USA). All other reagents were of analytical grade or better.

Non-essential amino acid solution (100×) and DMEM (high glucose) medium were purchased from Thermo Fisher Scientific. Fetal bovine serum was supplied by Biological Industries (Israel). $N$-[2-hydroxyethyl] piperazine- $N^{\prime}$-[4-butanesulfonic acid], penicillin and streptomycin solutions, and geneticin were obtained from Amresco (USA).

\section{Pharmacokinetic studies}

Twenty healthy male Sprague-Dawley (SD) rats (weighing 180-220 g, $n=5$ per group) were used for pharmacokinetic studies. They were purchased from the Beijing Institute of Pharmacology and Toxicology (China). Rats housed in polypropylene cages were kept under controlled temperature $\left(20-22{ }^{\circ} \mathrm{C}\right)$ and a 12-h day-night cycle. Animals were used for pharmacokinetic studies after 1-week acclimatization with food and water provided ad libitum.

Animal welfare and experimental procedures were approved by the Animal Ethics Committee of the Institute of Materia Medica, Shandong Academy of Medical Sciences (Jinan, China), and strictly complied with the guide for the care and use of laboratory animals (National Research Council of USA, 1996).

Jugular vein catheterization was performed as described previously (16). For bioavailability study, one group of rats was administered an intravenous dose $\left(10 \mathrm{mg} \mathrm{kg}^{-1}\right.$ via the tail vein) of morroniside. For oral pharmacokinetic studies, three groups of rats were administered an oral dose of 10, 30 and $90 \mathrm{mg} \mathrm{kg}^{-1}$ of morroniside, resp. Blood samples (150 $\mu \mathrm{L})$ were collected from the jugular vein into heparinized tubes before and at $2,5,15,30$, $45,60,120,240,360,480$ and 720 min after single i.v. dosing and 5, 15, 30, 45, 60, 120, 240, 360,480 and $720 \mathrm{~min}$ after single oral dosing. Samples were centrifuged at $3500 \mathrm{rpm}$ for 15 min at $4{ }^{\circ} \mathrm{C}$ and kept frozen at $-20^{\circ} \mathrm{C}$ prior to LC-MS/MS analysis. 
Pharmacokinetic parameters for morroniside were calculated by the Drug and Statistic (DAS) 2.0 pharmacokinetic software (Chinese Pharmacological Association, Anhui, China). $F_{(0-\infty)}(\%)$ was calculated by the following equation 1 :

$$
F_{(0-\infty)}=\frac{A U C_{(0-\infty)}\left(10 \mathrm{mg} \mathrm{kg}^{-1}{ }_{(\text {p.o. })}\right)}{A U C_{(0-\infty)}\left(10 \mathrm{mg} \mathrm{kg}^{-1}{ }_{\text {(i.v.) }}\right)}
$$

In situ permeability studies

Forty-eight healthy male SD rats (180-220 g, $n=4)$ were used for the in situ single-pass perfusion study. Rats were anesthetized via an intraperitoneal injection of $1 \%$ pentobarbital sodium $\left(40 \mathrm{mg} \mathrm{kg}^{-1}\right)$ and placed in a professional medical incubator to maintain the body temperature at $37^{\circ} \mathrm{C}$. The abdominal cavity was opened by a medioventral line incision, and approximately $10 \mathrm{~cm}$ of the duodenum, jejunum, ileum and colon segments were isolated carefully. The intestinal segment was intubated with a pliable plastic pipe at two ends and infused with Krebs-Ringer buffer $\left(7.8 \mathrm{~g} \mathrm{NaCl}, 0.35 \mathrm{~g} \mathrm{KCl}, 0.37 \mathrm{~g} \mathrm{CaCl}_{2}, 1.37 \mathrm{~g}\right.$ $\mathrm{NaHCO}_{3}, 0.32 \mathrm{~g} \mathrm{NaH}_{2} \mathrm{PO}_{4}, 0.02 \mathrm{~g} \mathrm{MgCl}_{2}, 1.4 \mathrm{~g}$ glucose and $20 \mathrm{mg}$ phenol red dissolved in $1000 \mathrm{~mL}$ distilled water with $\mathrm{pH}$ adjusted to 7.4) for $10 \mathrm{~min}$ with the flow rate set at $1.0 \mathrm{~mL}$ min $^{-1}$ using a single channel micro-infusion pump (WZ-50C66T, Smiths Medical Instrument, China). Subsequently, Krebs-Ringer buffer containing 15, 30 and $60 \mu \mathrm{g} \mathrm{mL}^{-1}$ morroniside was poured into the intestinal segment at a persistent flow rate of $0.2 \mathrm{~mL} \mathrm{~min}{ }^{-1}$ for about $1.5 \mathrm{~h}$. Perfusion fluid samples gained from the outlet of intestinal segments were gathered every $15 \mathrm{~min}$ after equilibration for $30 \mathrm{~min}$.

During the whole experiment, the exposed intestinal segments were maintained moist after cannulation with isotonic $0.9 \% \mathrm{NaCl}$ solution-moistened gauze and were kept at $37^{\circ} \mathrm{C}$. After in situ permeability studies, the radius and length of the duodenum, jejunum, ileum and colon segments were gauged (17).

$C_{\text {out(corr) }}\left(\mu \mathrm{g} \mathrm{mL} \mathrm{m}^{-1}\right.$, corrected outlet concentration of morroniside) and $P_{\text {eff }}\left(\mathrm{cm} \mathrm{s}^{-1}\right.$, quantitative measure of the rate of morroniside permeability across the biomembrane) were computed using the following equations:

$$
\begin{gathered}
C_{\text {out(corr) }}=\frac{C_{\text {out }} P R_{\text {in }}}{P R_{\text {out }}} \\
P_{\text {eff }}=\frac{Q \ln \left(C_{\text {in }} / C_{\text {out }(\text { corr })}\right)}{2 \pi r L}
\end{gathered}
$$

where $C_{\text {out }}\left(\mu \mathrm{g} \mathrm{mL} L^{-1}\right)$ is the uncorrected outlet concentration of morroniside, $P R_{\text {in }}$ and $P R_{\text {out }}$ $\left(\mathrm{mg} \mathrm{mL}^{-1}\right)$ are the inlet and outlet concentrations of phenol red, resp., $Q\left(0.2 \mathrm{~mL} \mathrm{~min}^{-1}\right)$ is the flow rate of the perfusate entering the rats' isolated intestinal segments, $C_{\text {out(corr) }}$ and $C_{\text {in }}$ are the corrected outlet and inlet concentrations of morroniside, resp., $r(\mathrm{~cm})$ and $L(\mathrm{~cm})$ are the radius and length of the perfused intestinal segment.

\section{Cell culture}

Caco-2 cells (American Type Culture Collection, USA) between passage 40 and 50 were used and cultured at $37^{\circ} \mathrm{C}$ in $5 \% \mathrm{CO}_{2}$ at $90 \%$ humidity in DMEM (high glucose) 
medium containing $15 \%$ fetal bovine serum, $1 \%$ non-essential amino acid solution, $100 \mathrm{U}$ $\mathrm{mL}^{-1}$ penicillin and $1 \%$ streptomycin. The DMEM medium was replaced twice a week. The cells were seeded in collagen-coated transwell inserts $(0.4-\mu \mathrm{m}$ pore size, $24-\mathrm{mm}$ diameter; Millipore, USA) at a density of $3 \times 10^{5}$ cells per insert. The cells were cultured for 21 days after seeding. The DMEM medium was replaced every two days.

\section{Cytotoxicity test}

The cytotoxicity test of morroniside to Caco-2 cells was performed using the MTT assay. The Caco-2 cells in the logarithmic growth phase were seeded onto a 96-well plate at a density of $1 \times 10^{5}$ cells per well in $100 \mu \mathrm{L}$ DMEM culture medium. After culturing at $37^{\circ} \mathrm{C}$ in $5 \% \mathrm{CO}_{2}$ for 3 days, the culture medium was replaced with $100 \mu \mathrm{L}$ of morroniside solution in HBSS (pH 7.4) at concentrations of 6.4, 32, 160, 800 and $4000 \mu \mathrm{mol} \mathrm{L}^{-1}$ and the HBSS (pH 7.4) was used as a blank control. Two hundred (200) $\mu \mathrm{L}$ of $5 \mathrm{mg} \mathrm{mL}^{-1}$ MTT solution in HBSS was added to each well after the plate was incubated at $37^{\circ} \mathrm{C}$ for $4 \mathrm{~h}$, and then the plate was incubated for another $4 \mathrm{~h}$. The medium was then replaced with $100 \mu \mathrm{L}$ of DMSO. The absorbance of the mixture in the 96 -well plate was measured at $570 \mathrm{~nm}$. The cytotoxicity of morroniside at different concentrations was calculated by the percentage of absorbance relative to that of the blank control.

\section{Transport studies}

Only cultures with transepithelial electrical resistance (TEER) (Millicell ERS ${ }^{\circledR}$, Millipore) values over $400 \Omega \mathrm{cm}^{-2}$ were employed for the flux experiment. Before the experiments, the Caco-2 cell monolayers were washed twice with incubation medium (HBSS, pH 7.4, $137 \mathrm{mmol} \mathrm{L}-1 \mathrm{NaCl}, 5.36 \mathrm{mmol} \mathrm{L} \mathrm{mCl}^{-1}, 0.952 \mathrm{mmol} \mathrm{L}^{-1} \mathrm{CaCl}_{2}, 0.812 \mathrm{mmol} \mathrm{L}^{-1} \mathrm{MgSO}_{4}$, $0.440 \mathrm{mmol} \mathrm{L}^{-1} \mathrm{KH}_{2} \mathrm{PO}_{4}, 0.385 \mathrm{mmol} \mathrm{L}^{-1} \mathrm{Na}_{2} \mathrm{HPO}_{4}, 25 \mathrm{mmol} \mathrm{L}^{-1} \mathrm{D}$-glucose and $25 \mathrm{mmol} \mathrm{L}^{-1}$ Hepes). Volumes of drug solution added to the apical (AP) and basolateral (BL) sides of the monolayer were $0.4 \mathrm{~mL}$ and $1.2 \mathrm{~mL}$, resp. The permeability of morroniside $(16,80$ and 400 $\mu \mathrm{mol} \mathrm{L}{ }^{-1}$ ) under all the above conditions for both directions, from the AP-to-BL side and from the BL-to-AP side, was measured at $37^{\circ} \mathrm{C}$. A $50-\mu \mathrm{L}$ aliquot of this incubation solution was withdrawn from the receiver compartment at 0, 15, 60 and $120 \mathrm{~min}$.

$P_{\text {app }}$ and $P_{\text {ratio }}$ were calculated by the following equations:

$$
\begin{gathered}
P_{\text {app }}=\frac{\Delta Q}{\Delta t A C_{0}} \\
P_{\text {ratio }}=\frac{P_{\text {app },(\mathrm{BL} \rightarrow \mathrm{AP})}(\text { mean })}{P_{\text {app },(\mathrm{AP} \rightarrow \mathrm{BL})}(\text { mean })}
\end{gathered}
$$

where $\Delta Q / \Delta t\left(\mu \mathrm{mol} \mathrm{s}^{-1}\right)$ is the permeation rate of morroniside, $A\left(\mathrm{~cm}^{2}\right)$ is the surface area of the epithelium $\left(0.33 \mathrm{~cm}^{2}\right)$ and $C_{0}\left(\mu \mathrm{mol} \mathrm{L}^{-1}\right)$ is the initial donor concentration of morroniside on the loading side. The $P_{\text {ratio }}$ of morroniside was obtained by dividing the $\mathrm{BL} \rightarrow \mathrm{AP}$ permeability by the $\mathrm{AP} \rightarrow \mathrm{BL}$ permeability.

\section{Determination of morroniside by HPLC-MS/MS}

The LC-MS/MS method has been already validated for the determination of morroniside in rat plasma over a concentration range of $2.0-5000 \mathrm{ng} \mathrm{mL}^{-1}$ with a lower limit of 
quantification (LLOQ) of $2.0 \mathrm{ng} \mathrm{mL}^{-1}$ (13). Chromatographic separation was carried out on an Inertsil C8-3 column using acetonitrile and water containing $1 \mathrm{mmol} \mathrm{L}^{-1}$ sodium formate at $0.4 \mathrm{~mL} \mathrm{~min}^{-1}$ for $6 \mathrm{~min}$. Linear gradient elution was applied. No interferences from endogenous substances were found at the retention times of either morroniside or IS. The intraand inter-day accuracy for morroniside ranged from 91.4 to $98.2 \%$ and 93.4 to $102.0 \%$, resp. Intra- and inter-day RSD for morroniside ranged from 4.3 to $5.1 \%$ and 5.0 to $7.7 \%$.

Data acquisition was performed using an API 5000 triple-quadrupole mass spectrometer coupled with an ESI source (Applied Biosystems/MDS SCIEX, USA) and Analyst software (version 1.5.1). The ESI source was operated with ion spray voltage of $5000 \mathrm{~V}$ and heater temperature of $550{ }^{\circ} \mathrm{C}$. Gas settings were as follows: curtain gas $15 \mathrm{~L} \mathrm{~h}^{-1}$, collision gas $5 \mathrm{~L} \mathrm{~h}^{-1}$, ion source gas 1: $30 \mathrm{~L} \mathrm{~h}^{-1}$, and ion source gas 2: $40 \mathrm{~L} \mathrm{~h}^{-1}$. Quantification was carried out by multiple reaction monitoring (MRM) in a positive ionization mode. Hyperoside was used as an internal standard (IS). Transitions selected for quantification were $\mathrm{m} / \mathrm{z}$ $429 \rightarrow 267$ for morroniside and $m / z 487 \rightarrow 324$ for IS. Collision energy values for morroniside and IS were 35 and $40 \mathrm{~V}$, respectively.

\section{Biosample preparation}

Frozen biosamples were thawed at room temperature and vortex-mixed. Fifty $\mu \mathrm{L}$ of biosample was mixed with $50 \mu \mathrm{L}$ water, $100 \mu \mathrm{L}$ IS working solution $\left(500 \mathrm{ng} \mathrm{mL}{ }^{-1}\right)$ and 150 $\mu \mathrm{L}$ methanol and vortex-mixed for $1 \mathrm{~min}$. After centrifugation at $14000 \mathrm{rpm}$ at $4{ }^{\circ} \mathrm{C}$ for 10 min, $10 \mu \mathrm{L}$ of supernatant was injected onto the LC-MS/MS system for analysis (13).

\section{Statistical analysis}

Experimental data were expressed as mean \pm standard deviation (SD). Statistical analysis was performed with the SPSS 20.0 software package (SPSS Inc., Chicago, IL, USA). Differences between the two groups were calculated by Student's $t$ test. Significance of the differences between groups for continuous variables was evaluated with one-way analysis of variance (ANOVA), the $\mathrm{mA}$ value of $p<0.05$ indicating statistical significance.

\section{RESULTS AND DISCUSSION}

In vivo permeability of morroniside

The LC-MS/MS method was successfully applied to the pharmacokinetic studies of morroniside at doses of 10 (i.v. and p.o.), 30 (p.o.), and 90 (p.o.) $\mathrm{mg} \mathrm{kg}^{-1}$ in rats. The pharmacokinetics of morroniside in rats within the used dosage ranges (10, 30 and $90 \mathrm{mg} \mathrm{kg}^{-1}$ ) after oral administration was in accord with linear pharmacokinetic characteristics. The linear regression equation between $A U C_{(0-t)}$ and the dose was $y=58.98 x-249.02\left(R^{2}=0.9827\right)$, while it was $y=19.77 x+87.65\left(R^{2}=0.9958\right)$ between $C_{\max }$ and the dose. Moreover, no apparent differences for $M R T, T_{1 / 2 \mathrm{z}}, T_{\max }, V_{\mathrm{d}}$ and $C L_{\mathrm{z}} / F$ were observed regardless of increasing doses.

The $A U C_{(0-t)}$ of morroniside after an intravenous dose $\left(10 \mathrm{mg} \mathrm{kg}^{-1}\right)$ to SD rats was $14673.84 \pm 3512.36 \mathrm{ng} \mathrm{h} \mathrm{mL}^{-1}$, compared with $610.84 \pm 361.61,1160.42 \pm 412.12$ and $5149.45 \pm$ $3557.32 \mathrm{ng} \mathrm{h} \mathrm{mL}^{-1}$ after an oral dose of $10,30,90 \mathrm{mg} \mathrm{kg}^{-1}$ of morroniside, resp. The pharmacokinetic study of morroniside within the used dosage ranges exhibited linear dose-proportional 

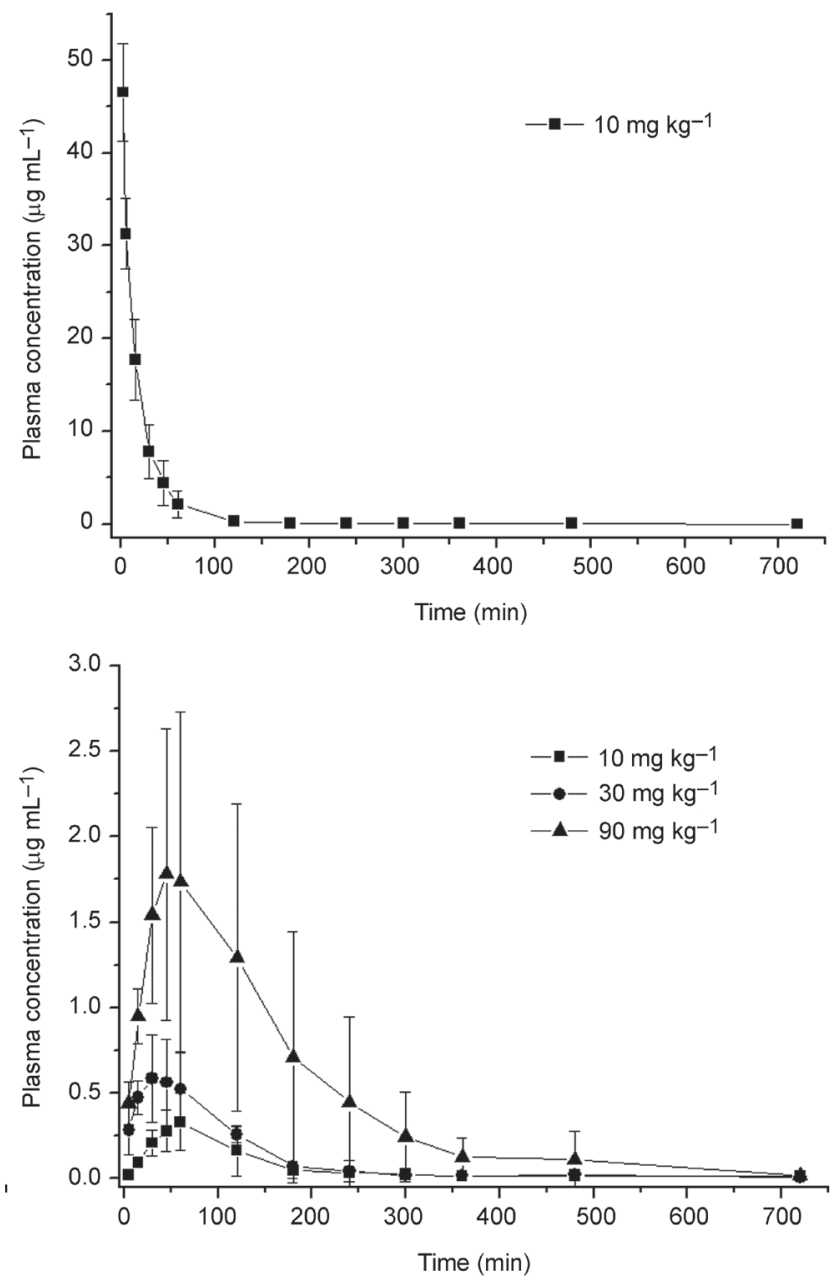

Fig. 1. Plasma concentration-time profiles of morroniside following: a) a single intravenous injection, and b) a single oral administration in rats (SD bars, $n=5)$.

pharmacokinetic characteristics and low bioavailability (4.3\%) in SD rats, which meant that only $4.3 \%$ of the prototype drug was absorbed into blood circulation. The plasma concentration-time profiles of morroniside after intravenous and oral administration of morroniside to rats are shown in Figs. 1a,b with the corresponding pharmacokinetic parameters given in Table I.

In situ permeability of morroniside

This was the first study to investigate the absorption mechanism of morroniside using a single-pass intestinal perfusion in situ model in SD rats. The stability of morroniside in 
Table I. Pharmacokinetic parameters of morroniside in rats

\begin{tabular}{ccccc}
\hline \multirow{2}{*}{ Parameter } & \multicolumn{4}{c}{ Treatment $\left(\mathrm{mg} \mathrm{kg}^{-1}\right)^{\mathrm{a}}$} \\
\cline { 2 - 5 } & $10(i . v)$. & $10($ p.o. $)$ & $30($ p.o. $)$ & 90 (p.o. $)$ \\
\hline$\left.A U C_{(0-t)}(\mathrm{ng} \mathrm{h} \mathrm{mL})^{-1}\right)$ & $14673.84 \pm 3512.36$ & $610.84 \pm 361.61$ & $1160.42 \pm 412.12$ & $5149.45 \pm 3557.32$ \\
$\left.A U C_{(0-\infty)}(\mathrm{ng} \mathrm{h} \mathrm{mL})^{-1}\right)$ & $14688.29 \pm 3509.75$ & $628.86 \pm 356.95$ & $1191.68 \pm 465.35$ & $5215.45 \pm 3610.10$ \\
$M R T_{(0-t)}(\mathrm{h})$ & $0.38 \pm 0.08$ & $1.62 \pm 0.49$ & $1.43 \pm 0.27$ & $1.90 \pm 0.58$ \\
$T_{1 / 2 z}(\mathrm{~h})$ & $1.77 \pm 0.35$ & $1.26 \pm 0.65$ & $1.40 \pm 1.17$ & $1.24 \pm 0.37$ \\
$T_{\max }(\mathrm{h})$ & $0.03 \pm 0.00$ & $1.00 \pm 0.00$ & $0.57 \pm 0.34$ & $1.05 \pm 0.57$ \\
$C L_{\mathrm{z}}\left(\mathrm{L} \mathrm{h}^{-1} \mathrm{~kg}^{-1}\right)$ & $0.71 \pm 0.17$ & $19.82 \pm 9.02$ & $27.59 \pm 7.89$ & $27.23 \pm 19.45$ \\
$V_{\mathrm{z}}\left(\mathrm{L} \mathrm{kg}^{-1}\right)$ & $1.88 \pm 0.76$ & $36.86 \pm 31.27$ & $49.61 \pm 35.04$ & $47.95 \pm 39.07$ \\
$C_{\max }\left(\mathrm{ng} \mathrm{mL}^{-1}\right)$ & $46530.00 \pm 5238.63$ & $329.60 \pm 168.27$ & $621.80 \pm 227.07$ & $1881.80 \pm 881.34$ \\
$F_{(0-\infty)}(\%)$ & - & 4.3 & - & - \\
\hline
\end{tabular}

${ }^{\mathrm{a}}$ Mean $\pm \mathrm{SD}, n=5$.

Table II. The $\mathrm{P}_{\text {eff }}$ values of three concentrations of morroniside in different intestinal segments

\begin{tabular}{ccccc}
\hline \multirow{2}{*}{$\begin{array}{c}\text { Morroniside } \\
\left.(\mu \mathrm{g} \mathrm{mL})^{-1}\right)\end{array}$} & Duodenum & Jejunum & Ileum & Colon \\
\cline { 2 - 5 } & $3.11 \pm 1.71$ & $3.63 \pm 1.48$ & $3.31 \pm 1.98$ & $3.09 \pm 2.03$ \\
\hline 15 & $4.30 \pm 2.15$ & $3.96 \pm 1.23$ & $4.53 \pm 0.94$ & $4.31 \pm 1.80$ \\
30 & $4.46 \pm 1.52$ & $4.13 \pm 1.78$ & $4.42 \pm 1.73$ & $4.28 \pm 1.64$ \\
60 & & & & \\
\hline
\end{tabular}

${ }^{\mathrm{a}}$ Mean $\pm \mathrm{SD}, n=4$.

Krebs-Ringer buffer at $37^{\circ} \mathrm{C}$ was investigated for at least $24 \mathrm{~h}$, which showed that morroniside was stable under the above conditions (data not published). Its average effective permeability coefficient ( $P_{\text {eff }}$ value) for transport across the small intestinal segments changed from $(3.09 \pm 2.03) \times 10^{-6}$ to $(4.53 \pm 0.94) \times 10^{-6} \mathrm{~cm} \mathrm{~s}^{-1}$. The $P_{\text {eff }}$ values were basically consistent irrespective of increasing concentrations of morroniside at the measured concentrations from 15 to $60 \mu \mathrm{g} \mathrm{mL}^{-1}$ after perfusion via duodenum, jejunum, ileum and colon segments (Table II). The $P_{\text {eff }}$ values were all close to $3.0 \times 10^{-6}$, which meant poor intestinal absorption (18) at three concentrations $\left(15,30\right.$, and $\left.60 \mu \mathrm{g} \mathrm{mL}{ }^{-1}\right)$.

Bi-directional transport of morroniside across Caco-2 cells

The in vitro study investigated the bi-directional transport of morroniside across Caco-2. The MTT assay was used to investigate morroniside cytotoxicity to Caco-2 cells in order to establish appropriate practical concentrations for bi-directional transport research. The result indicated that morroniside showed no toxic effect to Caco- 2 cells in the 


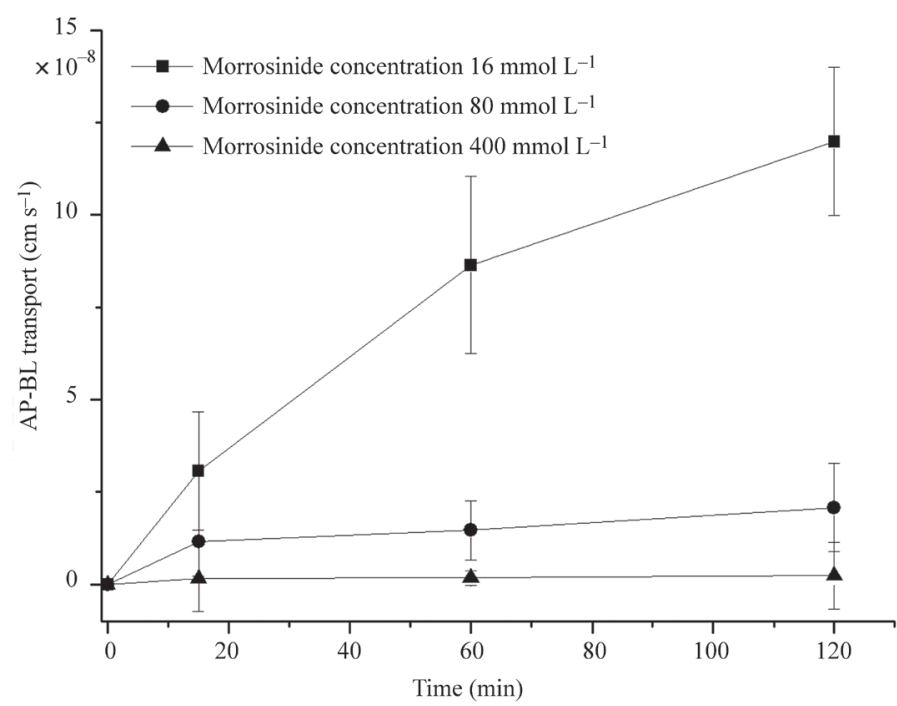

Fig. 2. Impact of time and concentration on morroniside absorption (SD bars, $n=3$ ).

Table III. The $\mathrm{P}_{\text {ratio }}$ of morroniside

\begin{tabular}{cccc}
\hline \multirow{2}{*}{$t(\min )$} & \multicolumn{3}{c}{$\mathrm{P}_{\text {ratio }}$ at morroniside concentration } \\
\cline { 2 - 4 } & $16\left(\mu \mathrm{mol} \mathrm{L}^{-1}\right)$ & $80\left(\mu \mathrm{mol} \mathrm{L}^{-1}\right)$ & $400\left(\mu \mathrm{mol} \mathrm{L}^{-1}\right)$ \\
\hline 15 & 0.01 & 0.01 & 0.6 \\
60 & 0.04 & 0.3 & 1.2 \\
120 & 0.05 & 0.5 & 1.2 \\
\hline
\end{tabular}

${ }^{\text {a }}$ Mean value, $n=3$.

concentration range from $6.4 \mu \mathrm{mol} \mathrm{L}-1$ to $4.0 \mathrm{mmol} \mathrm{L}^{-1}$. Morroniside concentrations $(16,80$, and $400 \mu \mathrm{mol} \mathrm{L}^{-1}$ ) were used to investigate the morroniside transport mechanism across the Caco-2 cell monolayer, which showed that the apparent permeability coefficient $\left(P_{\text {app }}\right)$ values of morroniside ranged from $(1.61 \pm 0.53) \times 10^{-9}$ to $(1.19 \pm 0.22) \times 10^{-7} \mathrm{~cm} \mathrm{~s}^{-1}$ for AP to BL. The efflux ratios $\left(P_{\text {ratio }}\right)$ at three concentrations were all lower than 1.2.

It could be inferred that the active uptake transport was involved in the absorption process of morroniside, because the $P_{\text {ratio }}$ values decreased with the increase in morroniside concentration. In addition, according to the obtained $P_{\text {ratio }}$ values from all concentrations and time points $\left(P_{\text {ratio }}\right.$ value $\left.<1.5\right)$, it could be concluded that morroniside might not be a substrate for P-gp (19), but active uptake transports might be involved in the transport of morroniside across the Caco-2 cell monolayer. The impact of time on morroniside absorption at the above concentrations is presented in Fig. 2. The $P_{\text {ratio }}$ values of morroniside are summarized in Table III. 


\section{CONCLUSIONS}

In conclusion, the present research studied in vivo, in situ, and in vitro absorption of oral morroniside. The pharmacokinetics of morroniside in rats within the used dosage ranges exhibited linear dose-proportional pharmacokinetic characteristics and low bioavailability. The in situ and in vitro results indicated that the intestinal transport of morroniside obeyed a concentration-independent active transport mechanism and the P-gp was not involved in morroniside transport. This research provided a rational explanation for the poor absorption of morroniside observed in pharmacokinetic experiments. For the above reasons, further investigations would be required to improve morroniside bioavailability.

Acknowledgments. - The project was financially supported by the National Major Scientific and Technical Special Projects for Innovative Drugs of China (Grant no. 2012ZX09301003-001-007); the Innovation Project of Shandong Academy of Medical Sciences and the Science and Technology Research Program of Shandong Academy of Medical Sciences (Grant no. 2016-41).

Acronyms, abbreviations, symbols. $-A$ - surface area of the epithelium, AP - apical side, AUC - area under curve, $\mathrm{BL}$ - basolateral side, $C_{0}$-initial donor concentration on the loading side, $C L_{\mathrm{z}}$ - clearance, $C_{\max }$ - peak concentration, $C_{\text {out }}$ - uncorrected outlet concentration, $C_{\text {in }}$ - corrected inlet concentration, $C_{\text {out(corr) }}$ - corrected outlet concentration, $\Delta Q / \Delta t$ - permeation rate, DMEM-Dulbecco's modified Eagle medium, $F$ - bioavailability, HBSS - Hank's balanced salt solution, $L$-length of the perfused intestinal segment, MRM - multiple reaction monitoring, MRT - mean residence time, $P_{\text {app }}$ - apparent permeability coefficient values, MTT - 3-(4,5-dimethylthiazole-2-yl)-2,5-diphenyl tetrazolium bromide, $P_{\text {eff }}-$ rate of permeability across a membrane, $\mathrm{P}$-gp $-\mathrm{P}$-glycoprotein, $P R_{\text {in }}$-inlet concentration of phenol red, $P R_{\text {out }}$ - outlet concentration of phenol red, $Q$ - perfusion flow rate through the intestinal segment, $r$ - radius of the perfused intestinal segment, $S D$ rats - Sprague Dawley rats, $T_{1 / 2 z}$ - half-life, TEER - transepithelial electrical resistance, $T_{\max }$ - peak time, $V_{z}$ - apparent volume of distribution.

\section{REFERENCES}

1. M. E. Czerwińska and M. F. Melzig, Cornus mas and Cornus Officinalis - Analogies and differences of two medicinal plants traditionally used, Front. Pharmacol. 9 (2018) Article ID 894 (28 pages); https://doi: 10.3389/fphar.2018.00894

2. H. K. Bhakta, C. H. Park, T. Yokozawa, B. S. Min, H. A. Jung and J. S. Choi, Kinetics and molecular docking studies of loganin, morroniside and 7-O-galloyl-D-sedoheptulose derived from Corni fructus as cholinesterase and $\beta$-secretase 1 inhibitors, Arch. Pharm. Res. 39 (2016) 794-805; https:// doi: 10.1007/s12272-016-0745-5

3. E. J. Jeong, T. B. Kim, H. Yang, S. Y. Kang, S. Y. Kim, S. H. Sung and Y. C. Kim, Neuroprotective iridoid glycosides from Cornus officinalis fruits against glutamate-induced toxicity in HT22 hippocampal cells, Phytomedicine 19 (2012) 317-321; https://doi: 10.1016/j.phymed.2011.08.068

4. C. H. Park, J. S. Noh, J. H. Kim, T. Tanaka, Q. Zhao, K. Matsumoto, N. Shibahara and T. Yokozawa, Evaluation of morroniside, iridoid glycoside from Corni fructus, on diabetes-induced alterations such as oxidative stress, inflammation, and apoptosis in the liver of type 2 diabetic $d b / d b$ mice, Biol. Pharm. Bull. 34 (2011) 1559-1565; https://doi.org/10.1248/bpb.34.1559

5. T. Yokozawa, N. Yamabe, H. Y. Kim, K. S. Kang, J. M. Hur, C. H. Park and T. Tanaka, Protective effects of morroniside isolated from Corni fructus against renal damage in streptozotocin-induced diabetic rats, Biol. Pharm. Bull. 31 (2008) 1422-1428; https://doi.org/10.1248/bpb.31.1422

6. C. H. Park, N. Yamabe, J. S. Noh, K. S. Kang, T. Tanaka and T. Yokozawa, The beneficial effects of morroniside on the inflammatory response and lipid metabolism in the liver of $d b / d b$ mice, Biol. Pharm. Bull. 32 (2009) 1734-1740; https://doi.org/10.1248/bpb.32.1734 
7. Y. Takeda, N. Tanigawa, F. Sunghwa, M. Ninomiya, M. Hagiwara, K. Matsushita and M. Koketsu, Morroniside cinnamic acid conjugate as an anti-inflammatory agent, Bioorg. Med. Chem. Lett. 20 (2010) 4855-4857; https://doi.org/10.1016/j.bmcl.2010.06.095

8. H. Oku, Y. Ogawa, E. Iwaoka and K. Ishiguro, Allergy-preventive effects of chlorogenic acid and iridoid derivatives from flower buds of Lonicera japonica, Biol. Pharm. Bull. 34 (2011) 1330-1333; https://doi.org/10.1248/bpb.34.1330

9. W. Wang, W. Huang, L. Li, H. Ai, F. Sun, C. Liu and Y. An, Morroniside prevents peroxide-induced apoptosis by induction of endogenous glutathione in human neuroblastoma cells, Cell. Mol. Neurobiol. 28 (2008) 293-305; https://doi.org/10.1007/s10571-007-9168-7

10. W. Wang, F. Sun, Y. An, H. Ai, L. Zhang, W. Huang and L. Li, Morroniside protects human neuroblastoma SH-SY5Y cells against hydrogen peroxide-induced cytotoxicity, Eur. J. Pharmacol. 613 (2009) 19-23; https://doi.org/10.1016/j.ejphar.2009.04.013

11. W. Wang, J. Xu, L. Li, P. Wang, X. Ji, H. Ai, L. Zhang and L. Li, Neuroprotective effect of morroniside on focal cerebral ischemia in rats, Brain Res. Bull. 83 (2010) 196-201; https://doi.org/10.1016/j. brainresbull.2010.07.003

12. P. Mehta, R. Shah, S. Lohidasan and K. R. Mahadik, Pharmacokinetic profile of phytoconstituent(s) isolated from medicinal plants - A comprehensive review, J. Tradit. Complement. Med. 5 (2015) 207-227; https://doi: 10.1016/j.jtcme.2014.11.041

13. S. Xiong, J. L. Li, X. Q. Zhu, X. Y. Wang, G. Y. Lv and Z. Q. Zhang, Determination of morroniside concentration in rat plasma by high performance liquid chromatography-tandem mass spectrometry, China J. Chin. Mater. Med. 38 (2013) 3378-3381.

14. S. Xiong, J. L. Li, X. Q. Zhu, X. Y. Wang, G. Y. Lv and Z. Q. Zhang, Determination of morroniside concentration in beagle plasma and its pharmacokinetics by high performance liquid chromatography-tandem mass spectrometry, Chin. J. Chromatogr. 33 (2014) 290-293.

15. S. Xiong, J. L. Li and Z. Q. Zhang, Excretion of morroniside in rat urine after single oral and intravenous administration, J. Chromatogr. Sci. 54 (2016) 912-917; https://doi.org/10.1093/chromsci/ bmw017

16. R. E. Buckingham, Indwelling catheters for direct recording of arterial blood pressure and intravenous injection of drugs in the conscious rat, J. Pharm. Pharmacol. 28 (1976) 459-461; https://doi. org/10.1111/j.2042-7158.1976.tb04660.x

17. P. Neerati, D. Ganji and S. K. Bedada, Study on in situ and in vivo absorption kinetics of phenytoin by modulating P-glycoprotein with verapamil in rats, Eur. J. Pharm. Sci. 44 (2011) 27-31; https:// doi: 10.1016/j.ejps.2011.05.005

18. U. Fagerholm, M. Johansson and H. Lennernäs, Comparison between permeability coefficients in rat and human jejunum, Pharm. Res. 13 (1996) 1336-1342.

19. J. L. Brunet, M. Maresca, J. Fantini and L. P. Belzunces, Human intestinal absorption of imidacloprid with Caco-2 cells as enterocyte model, Toxicol. Appl. Pharmacol. 194 (2004) 1-9; https://doi. org/10.1016/j.taap.2003.08.018 